\title{
Aplicação de silicatos de cálcio e de potássio e o crescimento de mudas de Eucalyptus grandis
} \author{
Fernando Márcio da Silva ${ }^{3}$ \\ ${ }^{1}$ Embrapa Florestas, Estrada da Ribeira, Km 111, CP 319, CEP 83.411-000, Colombo, PR, Brasil. \\ ${ }^{2}$ Bolsista Iniciação Científica CNPq, Pontifícia Universidade Católica do Paraná (PUC-PR), Brasil. \\ ${ }^{3}$ Suzano Papel e Celulose, Av. Dr. José Lembo, 1010, CEP 18.207-780, Itapetininga, SP, Brasil.
}

Itamar Antonio Bognola1, Lina Avila Clasen², Luziane Franciscon¹, José Luiz Gava ${ }^{3}$, Renato Antônio Dedecek¹,

\author{
"Autor correspondente: \\ iabog@cnpf.embrapa.br \\ Termos para indexação: \\ Silício \\ Adubação \\ Nutrição florestal \\ Index terms: \\ Silicon \\ Fertilization \\ Forest nutrition
}

Histórico do artigo:

Recebido em 19 ago 2010

Aprovado em 15 jun 2011

Publicado em 30 jun 2011

doi: $10.4336 / 2011 . p f b .31 .66 .83$
Resumo - O uso de silicato é uma prática que vem sendo adotada com frequência em culturas anuais, muito embora poucos trabalhos tenham sido realizados com intuito de verificar sua eficiência em espécies florestais arbóreas. O objetivo principal desta pesquisa foi avaliar o efeito da aplicação de silicatos de cálcio e de potássio no crescimento de mudas de Eucalyptus grandis. O experimento foi conduzido em casa de vegetação, no Município de Alambari, SP. O delineamento usado foi inteiramente ao acaso, com oito tratamentos, três repetições e 25 plantas por parcela, sendo mantidas na umidade de capacidade de campo. As mudas foram plantadas em tubetes de plástico, utilizando substrato local, com adubação básica e silicatos. Diâmetro de colo, altura e biomassa verde e seca das mudas foram determinados 150 dias após a aplicação dos silicatos. Verificou-se que a aplicação dos silicatos, via substrato ou foliar, em mudas de eucalipto, mostrou-se inadequada quando o substrato utilizado apresentou composição básica equilibrada em termos de nutrientes e $\mathrm{pH}$.

\section{Calcium and potassium silicates and the growth of Eucalyptus grandis seedlings}

\begin{abstract}
The use of silicate is a practice that has been frequently adopted in annual crops, although few studies have been conducted in order to verify its efficiency in forest tree species. The main objective of this research was to evaluate the effect of calcium and potassium silicates in the growth of seedlings of Eucalyptus grandis. The experiment was conducted in a greenhouse, in Alambari county, State of São Paulo. A completely randomized experimental design was adopted, with eight treatments, three replications and 25 plants per plot, maintained at the field capacity moisture level. Seedlings were planted in plastic tubes using local substrate, basic fertilization and silicates. Diameter, height and fresh and dry biomass of the seedlings were determined 150 days after silicates treatments were applied. The use of silicates either in the substrate or through foliar application, in the production of eucalypt seedlings has proven to be inadequate when the substrate presents a balanced basic composition in terms of nutrients and $\mathrm{pH}$.
\end{abstract}




\section{Introdução}

A implantação de florestas de eucalipto depende, dentre outros fatores, da utilização de mudas saudáveis, com bom diâmetro de colo, raízes bem formadas, relação adequada da parte aérea/sistema radicular e com bom estado nutricional. Isto pode garantir melhor índice de sobrevivência no plantio, maior resistência a estresses ambientais e maior crescimento inicial, influenciando diretamente na qualidade final da floresta (Ferrari, 2003).

Com relação à nutrição das mudas de eucalipto, o fósforo $(\mathrm{P})$ é um dos elementos que mais limita a produtividade. Normalmente, é o macronutriente que apresenta menor percentual de disponibilidade para as plantas devido à sua grande "fixação" e/ou lenta liberação das frações coloidais dos solos tropicais (Melo, 2005). Quando uma fonte solúvel de fósforo é adicionada em solos muito intemperizados, condição esta muito comum no Brasil, mais de $90 \%$ do que é aplicado fica adsorvido nas primeiras horas de contato com o solo. Com o passar do tempo, a continuidade da reação leva à fixação do fósforo (Gonçalves, 1988), ou seja, à passagem da forma lábil para não lábil. Considerase o fósforo fixado praticamente "indisponível" para as plantas.

Uma forma de compensar essa baixa disponibilidade para as plantas é a aplicação de elevadas quantidades de adubos fosfatados. No entanto, essa é uma prática que onera bastante os custos de implantação do eucalipto. Uma alternativa promissora é o uso de silicatos de cálcio ou de potássio, que fornecem o ânion silício (Si) que concorre com maior energia e eficiência pelos mesmos sítios de adsorção com o ânion fosfato, podendo incrementar a disponibilidade de fósforo $(\mathrm{P})$ na solução do solo para as plantas, resultando em aumento da produtividade da cultura. Contudo, não se deve deixar de lado o impacto que essas adubações podem causar ao meio ambiente, quando inadequadamente manejadas.

Dentre os materiais que fornecem silicatos, destacamse com potencial para o uso agrícola as escórias de alto forno, que são resíduos da indústria do aço e ferro e que apresentam em sua composição constituintes neutralizantes (Alcarde, 1992), especialmente cálcio $\left(\mathrm{Ca}^{2+}\right)$ e magnésio $\left(\mathrm{Mg}^{2+}\right)$, e metais não prejudiciais às plantas e ao solo (Piau, 1995). Isto implicaria na na redução de custos e passivos ambientais, ao reciclar estes resíduos industriais.

Apesar das informações disponíveis sobre a utilização de silicatos em diversas culturas, onde se observa a ação do silício na dessorção de fósforo, poucos esforços têm sido dedicados em estudos sobre o seu efeito em espécies arbóreas, como é o caso de Eucalyptus spp. (Carvalho et al., 2000, 2001 e 2003). Além disso, a necessidade de se aumentar a oferta de madeira oriunda de plantios florestais, principalmente para fins energéticos, torna imprescindível a introdução e o aperfeiçoamento de técnicas que contribuam de forma eficaz para o aumento da produtividade e a melhoria da qualidade das plantações de eucalipto, o que resultará em sistemas de produção sustentáveis, sem prejuízos ambientais, buscando fontes alternativas geradoras de bioenergia no Brasil (Crusciol \& Soratto, 2007).

Os objetivos do presente estudo foram avaliar o efeito da aplicação de silicatos de cálcio e de potássio no crescimento de mudas de eucaliptos em viveiro; avaliar se a fórmula do produto aplicado interfere na absorção de nutrientes pelas mudas de eucalipto e determinar a melhor forma e dosagem dos silicatos.

\section{Material e métodos}

Foi avaliado o efeito da aplicação de silicato na produção de mudas de Eucalyptus grandis com o uso de duas fontes de silício: silicato de cálcio $\left(\mathrm{CaSiO}_{3}\right)$ (aplicado no solo) e o silicato de potássio $\left(\mathrm{KSiO}_{3}\right)$ (aplicado nas folhas e no solo).

$\mathrm{O}$ experimento, em delineamento inteiramente casualisado, foi conduzido em viveiro, com oito tratamentos, com três repetições e 25 plantas por parcela, totalizando 600 mudas. Os tratamentos consistiram de:

T1 - testemunha, sem aplicação de silicatos (apenas adubação básica);

T2 - aplicação de silicato de cálcio via solo $(80 \mathrm{mg}$ planta $^{-1}$;

T3 - aplicação de silicato de cálcio via solo (160 mg planta $\left.^{-1}\right)$;

T4 - aplicação de silicato de cálcio via solo (320 mg planta $^{-1}$;

T5 - aplicação de silicato de potássio via foliar $(2,5 \mathrm{ml}$ $\mathrm{L}^{-1}$ de água);

T6 - aplicação de silicato de potássio via foliar $(5 \mathrm{ml}$ $\mathrm{L}^{-1}$ de água);

T7 - aplicação de silicato de potássio via foliar (10 $\mathrm{ml} \mathrm{L}^{-1}$ de água);

T8 - aplicação de silicato de potássio via solo $\left(0,1 \mathrm{mg} \mathrm{planta}^{-1}\right)$.

Todos os tratamentos apresentaram a seguinte composição básica para cada metro cúbico de substrato 
utilizado: 412 L de palha de arroz carbonizada; 353 L de vermiculita fina; $235 \mathrm{~L}$ de fibra de coco; $3 \mathrm{~kg}$ de osmocote; $4 \mathrm{~kg}$ de superfosfato simples zincado granulado.

Nos tratamentos com adição de silicatos ao solo, a aplicação foi feita uma única vez, misturando-se o silicato ao substrato. Já a adição foliar foi feita em aplicação, sendo a primeira aos 30 dias após a semeadura e as demais com intervalo de 30 dias.

Aos 150 dias após a semeadura, dez plantas de cada repetição, totalizando 240 mudas, foram submetidas à lavagem em água corrente e foram secas ao ar durante 24 horas. Na sequência, foram pesadas, tendo sido separada a parte aérea da raiz para obtenção da biomassa verde, e secadas em estufa a $50{ }^{\circ} \mathrm{C}$ até peso constante, com nova pesagem para obtenção da biomassa seca. Após trituradas, foram submetidas às análises químicas para avaliação do estado nutricional e verificados os teores de nutrientes e silício ( $\mathrm{Si}$ ) na matéria seca da parte aérea das mudas.

A estatística dos dados do experimento foi feita por meio da análise de variância para o modelo que considerou o efeito de tratamento. As diferenças entre os tratamentos foram observadas por contrastes ortogonais $(\mathrm{p}<0,05)$ e para o detalhamento entre as doses de silicato de potássio e de silicato de cálcio foi usada a regressão polinomial.

\section{Resultados e discussão}

De acordo com os níveis descritivos de probabilidade do teste $\mathrm{F}$ para as variáveis: altura, diâmetro, biomassa seca da parte aérea e biomassa verde da parte aérea de mudas de $E$. grandis, houve efeito significativo de tratamento $(\mathrm{p}>0,05)$ para todas as variáveis (Tabela 1$)$. Na Tabela 2 são apresentadas as médias e erros padrões das variáveis em função dos tratamentos e na Tabela 3, os contrastes ortogonais entre os tratamentos.

Tabela 1. Níveis descritivos de probabilidade do teste F para as variáveis analisadas.

\begin{tabular}{lc}
\hline \multicolumn{1}{c}{ Variáveis } & $\begin{array}{c}\text { Nível descritivo de } \\
\text { probabilidade }\end{array}$ \\
\hline Altura & $<0,001$ \\
Diâmetro & $<0,001$ \\
Biomassa Verde Aérea & $<0,001$ \\
Biomassa Seca Aérea & 0,0323 \\
\hline
\end{tabular}

Tabela 2. Médias e erros padrões para as variáveis em função dos tratamentos.

\begin{tabular}{lcccc}
\hline Variáveis & T1 & T2 & T3 & T4 \\
\hline Altura (cm) & $32,86 \pm 0,72$ & $29,02 \pm 0,72$ & $29,08 \pm 0,72$ & $28,65 \pm 0,72$ \\
Diâmetro (cm) & $2,76 \pm 0,09$ & $2,45 \pm 0,09$ & $2,51 \pm 0,09$ & $2,47 \pm 0,09$ \\
Biomassa Seca Aérea (g) & $1,22 \pm 0,09$ & $1,05 \pm 0,09$ & $1,01 \pm 0,09$ & $0,83 \pm 0,088$ \\
Biomassa Verde Aérea (g) & $2,18 \pm 0,14$ & $1,57 \pm 0,14$ & $1,19 \pm 0,14$ & $1,23 \pm 0,14$ \\
\hline Variáveis & T5 & T6 & T7 & T8 \\
\hline Altura (cm) & $31,16 \pm 0,72$ & $29,16 \pm 0,72$ & $31,08 \pm 0,72$ & $28,53 \pm 0,72$ \\
Diâmetro (cm) & $2,49 \pm 0,09$ & $2,93 \pm 0,09$ & $2,73 \pm 0,09$ & $2,88 \pm 0,09$ \\
Biomassa Seca Aérea (g) & $1,10 \pm 0,09$ & $0,96 \pm 0,088$ & $1,17 \pm 0,09$ & $1,19 \pm 0,09$ \\
Biomassa Verde Aérea (g) & $2,00 \pm 0,014$ & $1,43 \pm 0,14$ & $1,80 \pm 0,14$ & $1,41 \pm 0,14$ \\
\hline
\end{tabular}


Tabela 3. Contrastes ortogonais entre tratamentos.

\begin{tabular}{lcccc}
\hline Contrastes & Altura & Diâmetro & $\begin{array}{c}\text { Biomassa } \\
\text { verde aérea }\end{array}$ & $\begin{array}{c}\text { Biomassa } \\
\text { seca aérea }\end{array}$ \\
\hline T1 vs demais & $<0,001^{* * *}$ & $0,2230^{\mathrm{ns}}$ & $<0,001^{* * *}$ & $0,0706^{\mathrm{ns}}$ \\
T2 a T7 vs T8 & $0,1359^{\text {ns }}$ & $0,0039^{* *}$ & $0,4013^{\mathrm{ns}}$ & $0,0778^{\mathrm{ns}}$ \\
T2, T3, T4 vs & $0,0086^{* *}$ & $0,0013^{* *}$ & $<0,001^{* * *}$ & $0,1172^{\mathrm{ns}}$ \\
T5, T6, T7 & & & \\
***nível descritivo de probabilidade altamente significativo, ${ }^{* *}$ significativo, \\
ns não significativo.
\end{tabular}

No primeiro contraste, a testemunha (T1) é comparada com os demais tratamentos, sendo estatisticamente significativo $(\mathrm{p}<0,05)$ apenas para as variáveis altura e biomassa verde da parte aérea. Estes resultados mostram que o T1, em que não se aplicou silicato, foi o que apresentou quantitativamente os maiores valores das médias para as variáveis mencionadas (Tabelas 2 e 3 ).

O segundo contraste compara o grupo de tratamentos T2 a T7 com o tratamento T8. Esse contraste mostrou diferenças significativas $(\mathrm{p}<0,05)$ apenas para o diâmetro das mudas de eucalipto.

O terceiro contraste compara os tratamentos $\mathrm{T} 2, \mathrm{~T} 3$, T4 (silicato de cálcio via solo) versus T5, T6, T7 (silicato de potássio via foliar), o qual apresentou diferenças significativas $(\mathrm{p}<0,05)$ para altura, diâmetro e biomassa verde da parte aérea. Para tanto, utilizou-se a técnica de regressão polinomial com a intenção de verificar o efeito das diferentes doses de silicato de cálcio e silicato de potássio (Figura 1).
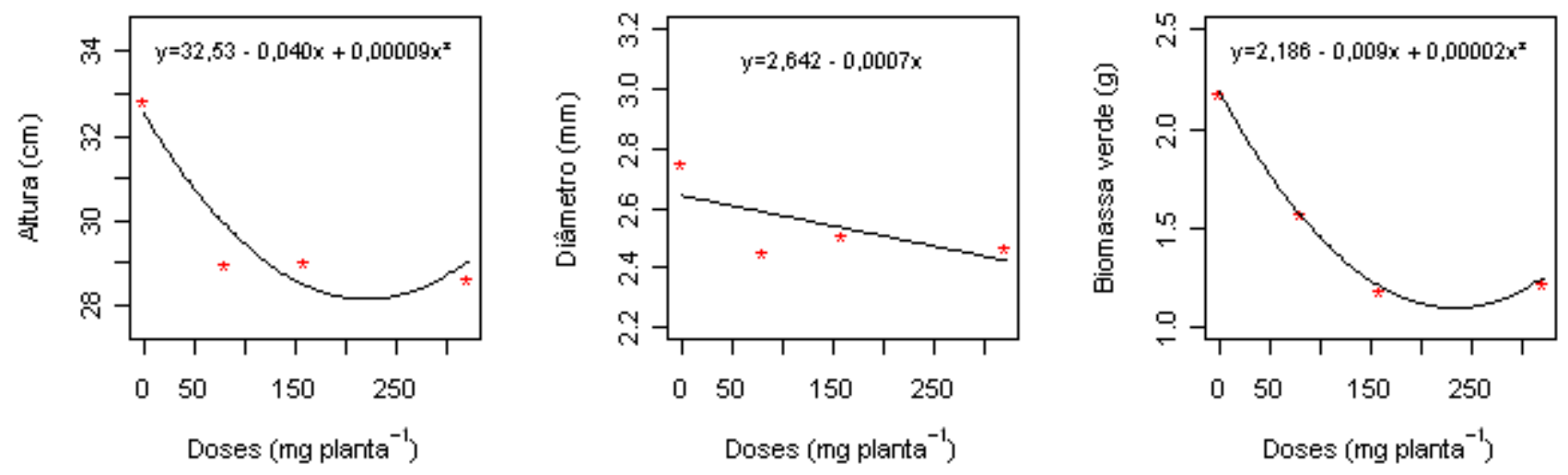

Figura 1. Médias e curvas ajustadas para altura, diâmetro e biomassa verde da parte aérea em função das doses de silicato de cálcio.

Foi observado para o silicato de cálcio um efeito linear negativo para a variável diâmetro, indicando que quanto maior a dose aplicada, menor foi o diâmetro das mudas de eucalipto. Para as variáveis altura e biomassa verde da parte aérea houve um efeito quadrático negativo e valor mínimo da altura de $222 \mathrm{mg}$ planta $^{-1}$, enquanto que para biomassa verde da parte aérea é de $225 \mathrm{mg} \mathrm{planta}^{-1}$.

Na Figura 2, observamos que para o silicato de potássio aplicado nas folhas, houve efeito quadrático para altura e biomassa verde da parte aérea.
Os resultados indicam que para essas variáveis existe uma dose que determina um valor mínimo e a partir dela ocorre aumento dos atributos avaliados. A dose de silicato de potássio que proporciona o valor mínimo de altura é $6,01 \mathrm{ml} \mathrm{L}^{-1}$ e para biomassa verde da parte aérea é $6,19 \mathrm{ml} \mathrm{L}^{-1}$.

Quanto às análises químicas da parte aérea de mudas de eucalipto, a Tabela 4 apresenta os níveis descritivos de probabilidade pelo teste F. Verifica-se que houve efeito significativo de tratamento $(\mathrm{p}<0,05)$ para cálcio, magnésio, potássio, cobre, nitrogênio, ferro e manganês. 

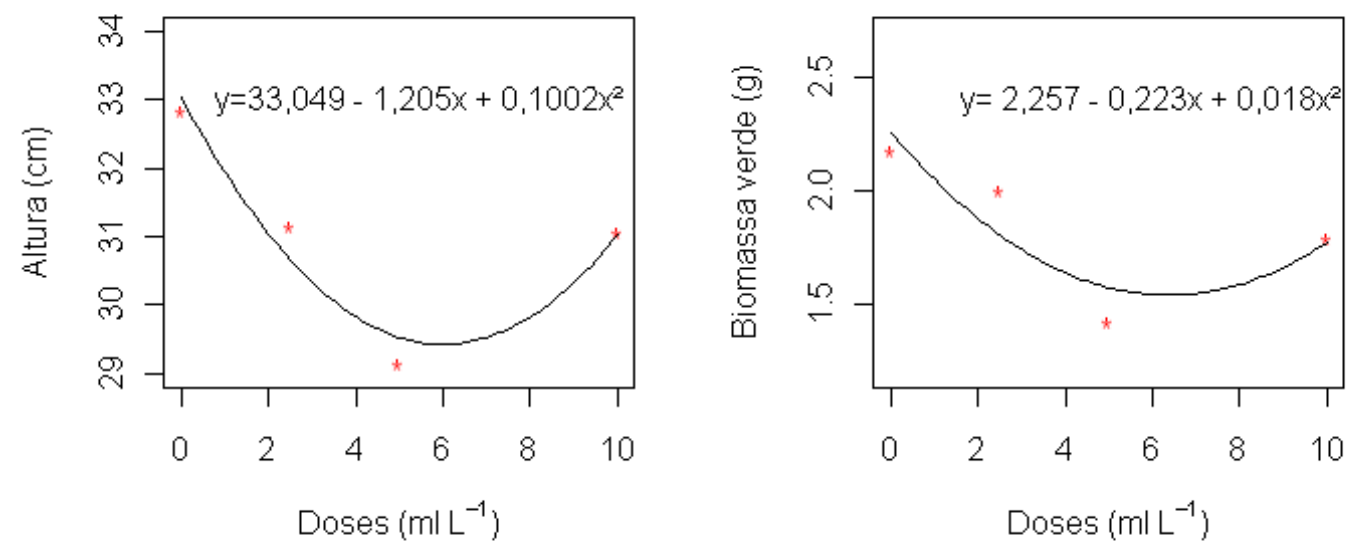

Figura 2. Médias e curvas ajustadas para altura, biomassa verde da parte aérea em função das doses de silicato de potássio.

Tabela 4. Níveis descritivos de probabilidade do teste F.

\begin{tabular}{lc}
\hline Variáveis & Nível descritivo de probabilidade \\
\hline Silício & 0,3495 \\
Fósforo & 0,1978 \\
Cálcio & 0,0017 \\
Magnésio & 0,0176 \\
Zinco & 0,1445 \\
Cobre & 0,0023 \\
Nitrogênio & 0,0457 \\
Ferro & 0,0224 \\
Potássio & $<0,001$ \\
Manganês & 0,0028 \\
\hline
\end{tabular}

Na Tabela 5 são apresentados os contrastes ortogonais relacionados à parte aérea das mudas. $\mathrm{O}$ primeiro contraste é de $\mathrm{T} 1$ versus os demais tratamentos e foi significativo $(\mathrm{p}<0,05)$ para as variáveis: cálcio, cobre, magnésio, potássio e manganês. $\mathrm{O}$ segundo contraste testa a diferença entre os tratamentos $\mathrm{T} 2$ a $\mathrm{T} 7$ versus o T8, esse contraste mostrou diferenças significativas $(\mathrm{p}<0,05)$ apenas para cálcio, potássio e nitrogênio. O terceiro contraste, T2, T3, T4 versus T5, T6, T7, apresentou diferenças significativas $(\mathrm{p}<0,05)$ para cálcio, ferro, magnésio, potássio e manganês.

Tabela 5. Contrastes ortogonais da parte aérea.

\begin{tabular}{lccccccc}
\hline Contrastes & Ca & Cu & Fe & Mg & Mn & N & K \\
\hline T1 vs demais & 0,0398 & $<0,001$ & 0,0575 & 0,0301 & 0,0138 & 0,1794 & 0,0020 \\
T2 a T7 vs T8 & $<0,001$ & 0,7805 & 0,0729 & 0,2146 & 0,0638 & 0,0017 & $<0,001$ \\
T2, T3, T4 vs T5, T6, T7 & 0,0055 & 0,1294 & 0,0068 & 0,0328 & $<0,001$ & 0,1857 & $<0,001$ \\
\hline
\end{tabular}

Comparando $\mathrm{T} 1 \mathrm{com}$ os demais tratamentos, nota-se que conforme houve aumento da dose de silicato de cálcio aplicado no solo, os teores de cálcio na planta eram mais elevados. As mudas provenientes de T1, assim como as que receberam adubação de silicato de potássio via foliar, apresentaram menores teores de cálcio na parte aérea. Estes teores de Ca nos diferentes tratamentos $\left(21,12\right.$ a $\left.24,82 \mathrm{~g} \mathrm{~kg}^{-1}\right)$ encontram-se bem acima dos valores considerados adequados por Martinez et al. (1999), que estão entre 8 a $12 \mathrm{~g} \mathrm{~kg}^{-1}$, e dos valores considerados adequados por Silveira et al. (2004), que estão na faixa de 7,1 a $11 \mathrm{~g} \mathrm{~kg}^{-1}$. É possível que isso tenha causado desequilíbrio na relação $\mathrm{Ca} / \mathrm{Mg}$, o que é prejudicial para a absorção de nutrientes.

$\mathrm{Na}$ Tabela 6 são apresentadas as médias e erros padrões das variáveis em função dos tratamentos. 
Tabela 6. Médias e erros padrões para as variáveis em função dos tratamentos.

\begin{tabular}{|c|c|c|c|c|}
\hline Variáveis & T1 & $\mathbf{T 2}$ & T3 & T4 \\
\hline Cálcio & $21,12 \pm 0,52$ & $22,39 \pm 0,52$ & $22,55 \pm 0,52$ & $23,16 \pm 0,52$ \\
\hline Cobre & $13,71 \pm 1,18$ & $19,65 \pm 1,18$ & $20,31 \pm 1,18$ & $20,67 \pm 1,18$ \\
\hline Ferro & $107 \pm 62,28$ & $213 \pm 62,28$ & $134 \pm 62,28$ & $90,62 \pm 62,28$ \\
\hline Fósforo & $3,54 \pm 0,12$ & $3,53 \pm 0,12$ & $3,54 \pm 0,12$ & $3,54 \pm 0,12$ \\
\hline Magnésio & $4,65 \pm 0,31$ & $5,18 \pm 0,31$ & $5,29 \pm 0,31$ & $5,13 \pm 0,31$ \\
\hline Manganês & $138 \pm 17,40$ & $138 \pm 17,40$ & $124 \pm 17,40$ & $119 \pm 17,40$ \\
\hline Nitrogênio & $9,89 \pm 0,70$ & $11,15 \pm 0,70$ & $12,50 \pm 0,86$ & $11,71 \pm 0,70$ \\
\hline Silício & $0,373 \pm 0,053$ & $0,410 \pm 0,053$ & $0,250 \pm 0,053$ & $0,263 \pm 0,053$ \\
\hline Potássio & $6,63 \pm 0,23$ & $6,84 \pm 0,23$ & $6,79 \pm 0,23$ & $8,42 \pm 0,23$ \\
\hline Zinco & $36,24 \pm 3,43$ & $39,17 \pm 3,43$ & $47,65 \pm 3,43$ & $46,18 \pm 3,43$ \\
\hline Variáveis & T5 & T6 & $\mathbf{T 7}$ & T8 \\
\hline Cálcio & $21,24 \pm 0,52$ & $21,13 \pm 0,52$ & $21,40 \pm 0,64$ & $24,82 \pm 0,52$ \\
\hline Cobre & $22,92 \pm 1,18$ & $20,20 \pm 1,18$ & $22,14 \pm 1,18$ & $20,62 \pm 1,18$ \\
\hline Ferro & $239 \pm 62,28$ & $399 \pm 62,28$ & $273 \pm 62,28$ & $354 \pm 62,28$ \\
\hline Fósforo & $3,41 \pm 0,12$ & $3,49 \pm 0,12$ & $3,21 \pm 0,12$ & $3,15 \pm 0,12$ \\
\hline Magnésio & $5,28 \pm 0,31$ & $5,45 \pm 0,31$ & $6,66 \pm 0,31$ & $5,06 \pm 0,31$ \\
\hline Manganês & $63,87 \pm 17,40$ & $64,13 \pm 17,40$ & $44,90 \pm 17,40$ & $54,98 \pm 17,40$ \\
\hline Nitrogênio & $11,15 \pm 0,70$ & $10,48 \pm 0,70$ & $11,25 \pm 0,70$ & $8,45 \pm 0,70$ \\
\hline Silício & $0,303 \pm 0,053$ & $0,267 \pm 0,053$ & $0,317 \pm 0,053$ & $0,360 \pm 0,053$ \\
\hline Potássio & $4,05 \pm 0,23$ & $4,55 \pm 0,23$ & $4,75 \pm 0,23$ & $4,62 \pm 0,23$ \\
\hline Zinco & $39,90 \pm 3,43$ & $37,84 \pm 3,43$ & $34,98 \pm 3,43$ & $36,61 \pm 3,43$ \\
\hline
\end{tabular}

Foram maiores os teores médios de cálcio e magnésio absorvidos pelas plantas de eucalipto nos diversos tratamentos quando aplicados via solo e comparados com a testemunha (Tabela 6). Como as mudas de eucalipto que tiveram aplicação de silicato apresentaram crescimento menor do que a testemunha, supõe-se ter havido elevação do $\mathrm{pH}$ do substrato, acima do ideal, o que deve ter dificultado a absorção dos outros macro e micronutrientes e pode ter provocado a precipitação de elementos essenciais. Considerando que o substrato já se encontrava devidamente equilibrado nutricionalmente, acredita-se que a aplicação de silicato interferiu negativamente na absorção de nutrientes pelas mudas.

Dantas (1992) e Rocha et al. (2008) também observaram um declínio no crescimento inicial de eucaliptos tanto em altura, quanto em diâmetro à altura do peito (DAP), com a aplicação de doses maiores do que $315 \mathrm{~g} \mathrm{cova}^{-1}$ de calcário. Isto pode ter ocorrido devido ao antagonismo entre os cátions no processo de absorção pelas raízes das plantas de eucalipto, ocasionado por excesso de calagem, causando um desequilíbrio entre os mesmos. Segundo Malavolta (2006), com o aumento do pH em função das doses elevadas de calcário, a disponibilidade da maioria dos micronutrientes é reduzida, o que está em concordância com os resultados aqui obtidos. Isso deve ter sido uma das causas que comprometeram o crescimento das plantas de eucalipto nos diversos tratamentos quando comparados com a testemunha.

Em geral, na adubação básica para produção de mudas de eucaliptos em viveiro, os níveis de $\mathrm{pH}$, $\mathrm{Ca}$ e $\mathrm{Mg}$ nos substratos utilizados neste sistema são adequados, de modo que a aplicação de calcário é dispensada e não recomendada, evitando-se assim problemas como a volatilização de $\mathrm{N}$ e a deficiência de micronutrientes induzida por níveis elevados de pH, dentre outros (Silva \& Stein, 2008). Esperava-se 
com a aplicação de silicato de cálcio e ou potássio que haveria um deslocamento de fósforo pelo silício nas frações coloidais do solo (Carvalho et al., 2000) e que haveria maior absorção do P pela planta, tornando-a mais produtiva, uma vez que o $\mathrm{pH}$ em torno de valores próximos a 6,5 seriam ideais para as mudas de eucaliptos.

Barros et al. (1997) e Lopes et al. (2007) comentam que devido à complexidade dos substratos existentes, as recomendações nutricionais para mudas de eucalipto são dificultadas; no entanto, utilizam-se fertilizantes de liberação lenta entre outras formulações, onde se preserva uma faixa ideal de $\mathrm{pH}$ (entre 5,5 e 6,0) para absorção adequada da maioria dos nutrientes.

Quanto aos níveis de potássio em E. grandis, segundo Boardman et al. (1997), são considerados deficientes os teores menores que $5 \mathrm{~g} \mathrm{~kg}^{-1}$ no estágio juvenil, os quais foram encontrados nos tratamentos T5, T6, T7 e T8, com aplicações de silicato de potássio nas folhas e no substrato; já os valores obtidos nos tratamentos T1 (testemunha) e T2, T3 e T4, com aplicações de silicato de cálcio via solo, foram considerados satisfatórios. Os resultados analíticos, em termos da concentração do elemento potássio nas folhas, são, no mínimo, intrigantes, uma vez que se esperaria exatamente $\mathrm{o}$ contrário, pois os silicatos de cálcio são desprovidos do elemento K. Os resultados de Boardman et al. (1997) contrastam com os resultados de Malavolta et al. (1997) que consideram os valores 6 a $8 \mathrm{~g}$ $\mathrm{kg}^{-1}$ também deficientes. Esta deficiência tem sido comumente encontrada nos plantios de eucaliptos, sendo caracterizada por clorose seguida de necrose marginal das folhas velhas (Silveira \& Malavolta, 2000).

A relação adequada entre $\mathrm{Ke} \mathrm{Ca}$ é fundamental para tornar máxima a absorção desses elementos, uma vez que o excesso de $\mathrm{K}$ pode reduzir a absorção de $\mathrm{Ca} \mathrm{e}$ vice-versa. Além dos elementos considerados essenciais, os benéficos como o silício podem estimular a absorção de outros nutrientes, dentre eles, o cálcio (Donegá, 2009). Os cátions monovalentes são absorvidos mais rapidamente pela raiz que os divalentes. Desta forma, o potássio compete fortemente na absorção do cálcio. Assim, a relação adequada entre eles é fundamental para tornar máxima a absorção desses elementos (Assis, 1995).

Os resultados apresentados na Figura 3 indicam que as doses de silicato de cálcio que proporcionam os valores máximos para cobre e nitrogênio são, respectivamente, 226,75 e $202 \mathrm{mg}$ planta $^{-1}$, ocasionando efeito quadrático para estes dois elementos. Dentro das diferentes dosagens de silicato de cálcio houve efeito linear para cálcio, ou seja, quanto maior a dose de silicato de cálcio, maior a quantidade de cálcio nas folhas das mudas de eucaliptos.
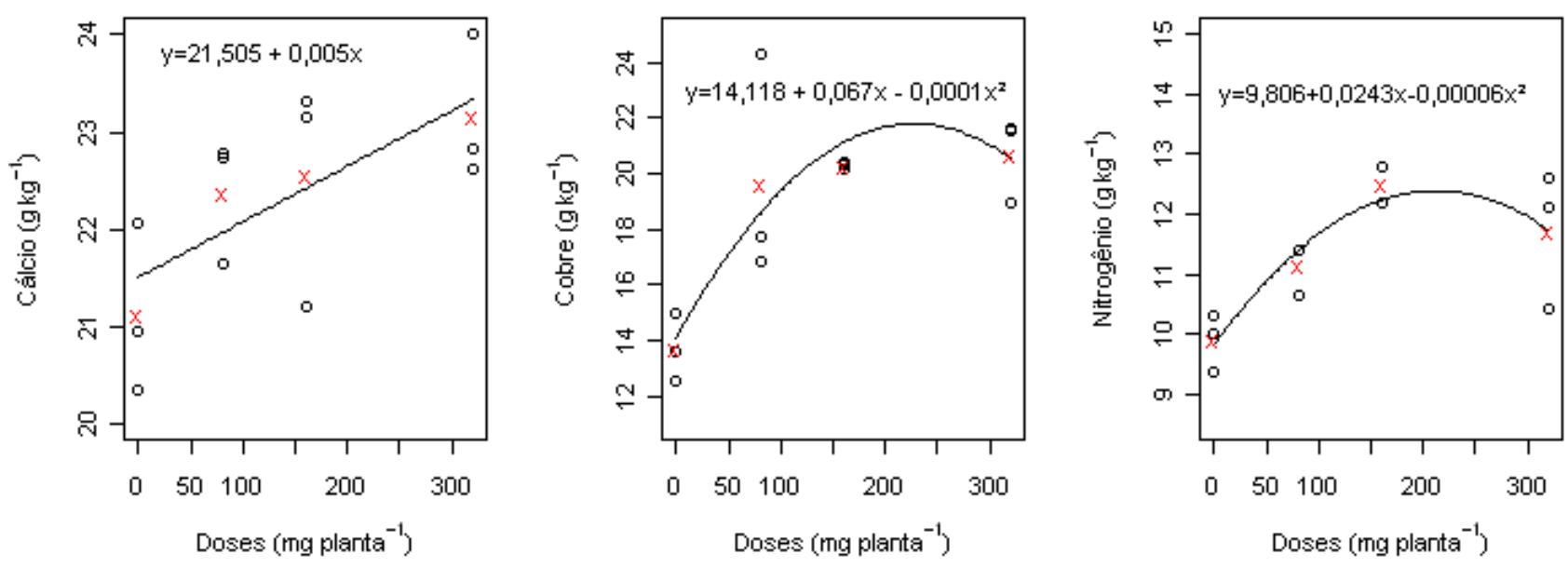

Figura 3. Médias e curvas ajustadas para cálcio, cobre e nitrogênio em função das doses de silicato de cálcio (biomassa verde parte aérea). 
Na Figura 4, verifica-se que com aplicação de silicato de potássio, o magnésio apresentou efeito linear, ou seja, quanto maior a dosagem de silicato, maior o nível de $\mathrm{Mg}^{2+}$ disponível na planta. Para ferro e manganês, observou-se efeito quadrático, sendo a dose que determina o valor máximo é $6,25 \mathrm{ml} \mathrm{L}^{-1}$ para ferro e, para manganês, a dose que determina o valor mínimo é $7,72 \mathrm{ml} \mathrm{L}^{-1}$.
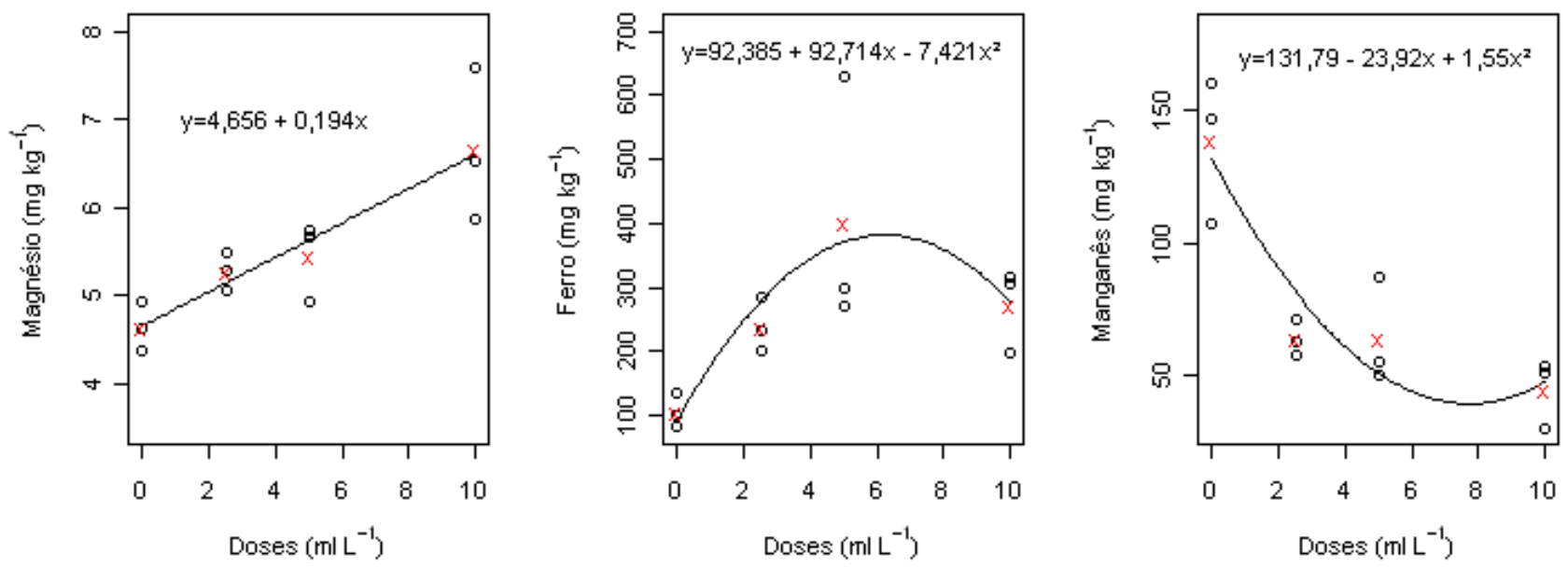

Figura 4. Médias e curvas ajustadas para magnésio, ferro e manganês em função das doses de silicato de potássio (biomassa verde parte aérea).

Os valores dos teores de $\mathrm{Mn}$ nas folhas das mudas de eucalipto variaram de 119 a $138 \mathrm{mg} \mathrm{kg}^{-1}$ nos tratamentos com aplicação de silicato de cálcio e variaram de 45 a $64 \mathrm{mg} \mathrm{kg}^{-1}$ nos tratamentos com aplicação de silicato de potássio. Portanto, encontram-se dentro e abaixo, respectivamente, da faixa adequada (100 a $\left.600 \mathrm{mg} \mathrm{kg}^{-1}\right)$ citada por Martinez et al. (1999). Por outro lado, ambos estão abaixo da faixa crítica (200 a $840 \mathrm{mg} \mathrm{kg}^{-1}$ ) apontada por Silveira et al. (2004).

\section{Conclusões}

A aplicação de silicatos, tanto de cálcio quanto de potássio, em substrato para mudas de eucalipto, se mostrou inadequada em decorrência do mesmo já possuir uma composição básica equilibrada em termos de nutrientes e $\mathrm{pH}$.

\section{Referências}

ALCARDE, J. C. Corretivos da acidez dos solos: características e interpretações técnicas. 2. ed. São Paulo: ANDA, 1992. 26 p. (Boletim Técnico, 6).
ASSIS, R. P. de. Nutrição mineral e crescimento de mudas de dendezeiro (Elaeis guinensis Jacq.) em função de diferentes relações entre K, Ca e Mg na solução nutritiva. 1995. 41 f. Dissertação (Mestrado em Solos e Nutrição de Plantas) Universidade Federal de Lavras, Lavras, MG.

BARROS, N. F.; NEVES, J. C. L.; NOVAIS, R. F. Nutrição e adubação de eucalipto. Informe Agropecuário, Belo Horizonte, v. 18, n. 186, p. 70-75, 1997.

BOARDMAN, R.; CROMER, R. N.; LAMBERT, M. J.; WEBB, M. J. Forest plantations. In: REUTER, D. J.; ROBINSON, J. B. Plant analysis an interpretation manual. 2. ed. Collingwood: CSIRO, 1997. p. 505-566.

CARVALHO, R.; FURTINI NETO, A. E.; CURI, N.; FERNANDES, L. A.; OLIVEIRA JUNIOR, A. C. Dessorção de fósforo por silício em solos cultivados com eucalipto. Revista Brasileira de Ciência do Solo, Viçosa, MG, v. 24, p. 69-74, 2000.

CARVALHO, R.; FURTINI NETO, A. E.; SANTOS, C. D. dos; FERNANDES, L. A.; CURI, N.; RODRIGUES, D. de C. Interações silício-fósforo em solos cultivados com eucalipto em casa de vegetação. Pesquisa Agropecuária Brasileira, Brasília, DF, v. 36, n. 3, p. 557-565, 2001.

CARVALHO, R.; FURTINI NETO, A. E.; CURI, N.; RESENDE, A. V. Absorção e translocação de silício em mudas de eucalipto cultivadas em latossolo e cambissolo. Ciência Agrotécnica, Lavras, MG, v. 27, n. 3, p. 491-500, maio/jun., 2003. 
CRUSCIOL; C. A. C; SORATTO, R. P. Utilização de silício aumenta a produtividade comercial da batata. 2007 . Disponível em: <http://www.infobibos.com/Artigos/2007_2/ silicio/index.htm>. Acesso em: 04 abr. 2010. Site do Infobibos.

DANTAS, C. E. S. Crescimento e composição mineral de mudas de eucalipto produzidas em composto orgânico em função da aplicação de fertilizantes minerais. 1992. $61 \mathrm{f}$. Dissertação (Mestrado em Engenharia Florestal) - Universidade Federal de Viçosa, Viçosa, MG. <completar...Mestrado em...>

DONEGÁ, M. A. Relação K/Ca e aplicação de silício na solução nutritiva para o cultivo hidropônico de coentro. 2009. 62 f. Dissertação (Mestrado em Ciências) - Escola Superior de Agricultura "Luiz de Queiroz", Universidade de São Paulo, Piracicaba, SP.

FERRARI, M. P. Sistema de produção de mudas. In: SILVA, H. D. da (Org.). Cultivo do eucalipto. Colombo: Embrapa Florestas, 2003. (Embrapa Florestas. Sistemas de produção, 4). Disponível em: <http://sistemasdeproducao.cnptia.embrapa.br/FontesHTML/ Eucalipto/CultivodoEucalipto/03_producao_de_mudas.htm.> Acesso em: 28 jul.2010.

GONÇALVES, J. L. M. Cinética de transformação de fósforo lábil em não lábil em amostras de solos de cerrado. 1988. 62 f. Tese (Doutorado) - Universidade Federal de Viçosa, Viçosa, MG.

LOPES, J. L.; GUERRINI, I. A.; SAAD, J. C. C.; SILVA, M. R. Nutrição mineral de mudas de eucalipto produzidas sob diferentes lâminas de irrigação e substratos. Revista Brasileira de Ciência de Solo, v. 31, n. 4, p. 713-722, 2007.

MALAVOLTA, E. Manual de nutrição mineral de plantas. São Paulo: Agronômica Ceres, 2006. 638 p.

MALAVOLTA, E.; VITTI, G. C.; OLIVEIRA, S. A. Avaliação do estudo nutricional das plantas: princípios e aplicações. 2. ed. Piracicaba, SP: Associação Brasileira para a Pesquisa do Potassa e do Fosfato, 1997. 319 p.
MARTINEZ, H. E. P.; CARVALHO, J. G.; SOUZA, R. B. Diagnose foliar. In: RIBEIRO, A. C.; GUIMARÃES, P. T. G.; ALVARES V. V. H. (Eds.). Recomendações para o uso de corretivos e fertilizantes em Minas Gerais: $5^{\text {a }}$ aproximação. Viçosa, MG: Comissão de Fertilidade do Solo do Estado de Minas Gerais, 1999. p. 143-167.

MELO, S. P. de. Silício e fósforo para estabelecimento do capim-marandu num latossolo vermelho-amarelo. 2005. $110 \mathrm{f}$. Tese (Doutorado em Agronomia). Escola Superior de Agricultura "Luiz de Queiroz”, Universidade de São Paulo, Piracicaba, SP.

PIAU, W. C. Efeito de escória de siderurgia em atributos químicos de solos e na cultura do milho (Zea mays L). 1995. 124 f. Tese (Doutorado em Solos e Nutrição de Plantas) - Escola Superior de Agricultura "Luiz de Queiroz", Universidade de São Paulo, Piracicaba, SP..

ROCHA J. B. O.; POZZA, A. A. A.; CARVALHO, J. G.; SILVA, C. A.; CURI, N. Efeito da calagem na nutrição mineral e no crescimento inicial do eucalipto a campo em Latossolo Húmico da Zona da Mata (MG). Scientia Forestalis, v. 36, n. 80, p. 255-263, 2008.

SILVA, P. H. M. da; STEIN, L. M. Produção de Mudas e Recomendações de Adubação no Viveiro para Pequenos Produtores. 2008. Disponível em: $<$ http://www.ipef.br/ silvicultura/producaomudas.asp $>$. Acesso: 13 jul. 2010. Site do IPEF.

SILVEIRA, R. L. V. A.; HIGASHI, E. N.; GONÇALVES, A. N.; MOREIRA, A. Evaluation of the nutritional status of eucalypts: visual and foliar diagnoses and their interpretation. In: GONÇALVES, J. L. M.; BENEDETTI, V. (Eds.). Forest nutrition and fertilization. Piracicaba, SP: IPEF, 2004. p. 79104.

SILVEIRA, R. L. V. A.; MALAVOLTA, E. Nutrição e adubação potássica. Informações Agronômicas, n. 91, set. 2000. (Encarte técnico). 
